\title{
Entre roças e florestas: passado e presente na Mata Atlântica do estado do Rio de Janeiro
}

\section{Between shifting cultivation and forests: past and present in the Atlantic Forest of the State of Rio de Janeiro}

\section{Entre rozas y bosques: pasado y presente en el Bosque Atlántico del estado de Rio de Janeiro}

http://dx.doi.org/10.21713/2358-2332.2016.v13.1095

Rogério Ribeiro de Oliveira, doutor em Geografia pela Universidade Federal do Rio de Janeiro (UFRJ), professorassociado do Departamento de Geografia e Meio Ambiente e dos Programas de Pós-Graduação de Geografia e de Engenharia Urbana e Ambiental da Pontifícia Universidade Católica do Rio de Janeiro (PUC-RJ), Rio de Janeiro, RJ, Brasil. E-mail: rro@puc-rio.br.

Annelise Caetano Fraga Fernandez, doutora em Sociologia e Antropologia pela Universidade Federal do Rio de Janeiro (UFRJ), professora adjunta do Departamento de Ciências Sociais e do Programa de Pós-Graduação em Ciências Sociais da Universidade Federal Rural do Rio de Janeiro (UFRRJ), Rio de Janeiro, RJ, Brasil E-mail: annelisecff@yahoo.com.br.

\section{Resumo}

Este trabalho trata da coexistência de ambientes florestais com ambientes agrícolas em duas áreas da Mata Atlântica na região Sudeste do Brasil. Uma está localizada na Ilha Grande (litoral sul do estado do Rio de Janeiro), sua superfície é quase toda coberta por florestas, que, em sua maior parte, recobriram áreas anteriormente cultivadas pelos caiçaras. $A$ outra área é o Maciço da Pedra Branca (na zona oeste da cidade do Rio de Janeiro), também recoberta por florestas secundárias onde ainda existem alguns cultivos. Nesta última, estuda-se a relação dos agricultores com 
a dinâmica de crescimento da cidade. Nos dois casos, examinam-se os conflitos e particularidades advindos da coexistência de unidades de conservação com comunidades de plantadores e as consequências perante a dinâmica da Mata Atlântica. O registro dessas experiências, por meio de uma perspectiva interdisciplinar de longa duração sobre a paisagem, pode trazer novos enfoques sobre os processos de coevolução das sociedades humanas com o meio natural.

Palavras-chave: Populações Tradicionais. Agricultura de Subsistência. Florestas Secundárias. Turismo Comunitário.

\section{Abstract}

This work addresses the coexistence of forests with agricultural environments in two areas of the Atlantic Forest in Southeastern Brazil. One is located on Ilha Grande (South coast of the State of Rio de Janeiro) with almost $100 \%$ of forest cover, most of which was previously cultivated by caiçaras. The other area is the Pedra Branca Massif (in the West Zone of the city of Rio de Janeiro), also covered by secondary forests where there are still some crops. In the latter, we studied the farmers' relationship with the city's growth dynamics. In both cases, the conflicts and peculiarities arising from the coexistence of protected areas with small agricultural communities and the consequences related to the Atlantic Forest dynamics are examined. The recording of these experiences, by means of a longterm interdisciplinary perspective on landscape, can bring new approaches to the processes of co-evolution of human societies with the natural environment.

Keywords: Traditional Populations. Slash-and-burn Agriculture. Secondary Forests. Community Tourism.

\section{Resumen}

Este trabajo trata de la coexistencia de ambientes forestados con ambientes agrícolas en dos áreas del Bosque Atlántico en el Sureste 
brasileño. Uno está localizado en Ilha Grande (litoral sur del estado de Rio de Janeiro) y su superficie está casi toda cubierta por bosques, que en su mayor parte se sobreponen a áreas que fueron cultivadas anteriormente por los caiçaras. La otra área es el macizo de Pedra Branca (zona oeste de la ciudad de Rio de Janeiro), también cubierta por bosques secundarios donde todavía existen algunos cultivos. En esta última se estudia la relación de los agricultores con la dinámica de crecimiento de la ciudad. En los dos casos se examinan los conflictos y las particularidades derivadas de la coexistencia de unidades de conservación con comunidades agrícolas y sus consecuencias frente a la dinámica del Bosque Atlántico. El registro de estas experiencias, por medio de una perspectiva interdisciplinar de larga duración sobre el paisaje, puede traer nuevos enfoques sobre los procesos de coevolución de las sociedades humanas con el medio natural.

Palabras clave: Poblaciones Tradicionales. Agricultura de Subsistencia. Bosques Secundarios. Turismo Comunitario.

\section{INTRODUÇÃO}

Em uma perspectiva histórica, é evidente o legado ambiental deixado para a atualidade no território brasileiro, o qual é produto das relações de populações passadas com o meio. O longo histórico de transformação das condições ambientais é uma resultante da forma com que suas populações - sejam elas compostas por sambaquieiros, índios, miscigenados, imigrantes ou afrodescendentes - interagiram ou ainda interagem com o ambiente. A Mata Atlântica, tal como a conhecemos hoje, pode ser interpretada como um documento histórico que potencialmente evidencia e descreve - em inúmeros atributos - o produto da interação de seres humanos com o ecossistema. O resgate da história desses usos superpostos dos espaços é de grande importância para o entendimento da dinâmica dos ecossistemas. Abordagens de diversas disciplinas podem ser adotadas nessa questão, que tem na paisagem seu foco central.

O estudo da paisagem requer sua desnaturalização como realidade imediata para uma totalidade, pois é resultado da mediação daquele que a interpreta, experimenta ou a apresenta. De acordo com Simmel (2009), 
a paisagem é um fragmento, um recorte do todo, mas ao ser elaborada torna-se um todo independente. Raffestin (2007, p. 8) a define como "[...] uma outra maneira de exprimir a porção de território real e material que é objeto de uma ou várias representações segundo a ou as linguagens escolhidas". Nesse sentido, a cooperação entre a Ecologia, a Geografia, a História e as Antropologias em interação com os saberes locais ou tradicionais contribui para a compreensão de dimensões integradas da paisagem por meio da articulação de suas respectivas linguagens.

Questões culturais interferem fortemente no legado ambiental dos processos pelos quais passou a paisagem. Segundo Ouis e Jensen, (2009, p. 130), a própria diversidade biológica é

[...] associada mais ou menos inconscientemente a uma ordem mais antiga, com as circunstâncias pré-modernas. Em termos metafóricos, estéticos e ideológicos, a diversidade pode ser considerada como uma reação à ordem, à monocultura e à eficiência da sociedade moderna?'

A paisagem é, portanto, um locus de interação dotada de uma dimensão temporal, que é tanto histórica e cultural quanto evolutiva e física, sobre a qual eventos passados encontram-se inscritos, por vezes sutilmente (BALÉE, 2006). Assim, se de fato registra-se o avanço inexorável de novas relações socioprodutivas, que alteram modos de vida e as formas de interação com a natureza, a paisagem registra as formas de resiliência, adaptação e reinvenção de modos de vida tradicionais.

${ }^{1}$ Tradução livre dos autores. No original: "Biological diversity is more or less unconsciously associated with an older order, with premodern circumstances. Metaphorically, aesthetically and ideologically, diversity can be said to be a reaction to the order, monoculture and efficiency of modern society". curtas distâncias. A diversidade da Floresta Atlântica está ligada a uma grande heterogeneidade espacial, em função de diferentes latitudes, altitudes e usos históricos. Parte muito considerável das áreas florestadas (principalmente no domínio da Floresta Ombrófila Densa Submontana) apresenta vestígios diversos como baldrames e fundações de casas, fragmentos de carvão no solo, espécies exóticas ou escapadas de cultivo, evidenciando, assim, o uso anterior de vastas áreas de florestas de situações em que os elementos florísticos e faunísticos alteram-se a 
secundárias. Essa situação é onipresente na Serra do Mar (OLIVEIRA; ENGEMANN, 2012).

Além disso, em função de usos anteriores diversos (principalmente a agricultura de subsistência), a grande maioria dos remanescentes é composta por florestas secundárias muito fragmentadas e submetidas a pressões diversas. São muito escassas as áreas de floresta de encosta sem vestígio de usos anteriores, mas podem ser encontradas em algumas vertentes declivosas, em encostas com grande número de matacões ou em linhas de cumeadas (OLIVEIRA, 2008). A maioria das demais áreas florestadas (principalmente o domínio da Floresta Ombrófila Densa Submontana) apresenta os vestígios supracitados, explicando, assim, a substantiva ocorrência de vastas áreas de florestas secundárias. Essa situação, com poucas variações, repete-se em numerosos trechos da Serra do Mar. Essas formações secundárias apresentam um impacto global bastante positivo, pois têm implicações no sequestro de carbono, na biodiversidade regional e na estabilidade do solo. (CHAZDON, 2014).

Processos adaptativos de longa duração entre plantas e humanos têm colocado em evidência o componente cultivado da biodiversidade - a agrobiodiversidade - seja por sua potencialidade de descrição de uma paisagem híbrida entre humanos e não humanos com múltiplas temporalidades, seja por trazer ao debate público a importância da proteção da biodiversidade agrícola e não apenas de plantas e animais silvestres. Incluímos o Direito como área de conhecimento fundamental no halldos estudos interdisciplinares da paisagem, à medida que o debate sobre o merecimento de proteção nas relações sociedade-natureza resulta na produção de códigos e medidas legais as quais, por sua vez, exercem seus efeitos sobre os estudos e políticas ambientais.

Este trabalho pretende examinar a coexistência de populações tradicionais e suas roças com a floresta atlântica. Para tanto, são estudadas duas situações, com usos semelhantes, em locais igualmente transformados em unidades de conservação (UCs), mas que apresentaram resultantes ecológicas e dinâmicas socioespaciais diferentes. Nosso objetivo, portanto, é chamar atenção para um promissor campo de 
estudos voltados para a multidimensionalidade própria da paisagem, que incorpora tanto sua manifestação ecológica como o registro cultural da milenar e atual interação do homem, contribuindo, assim, para uma maior compreensão dos processos de transições culturais por que passam as populações tradicionais.

No primeiro caso, estuda-se o uso histórico da terra por populações caiçaras na llha Grande, localizada no litoral sul do estado do Rio de Janeiro. Embora suas roças tenham ocupado parte considerável do território da Ilha Grande, atualmente, elas encontram-se em declínio, sendo ainda encontradas em pequena escala nas proximidades de vilas. De acordo com Costa (2011), a maioria dos moradores abandonou as atividades de pesca embarcada e de agricultura de subsistência para viver do turismo comunitário, embora algumas famílias ainda mantenham atividades agrícolas como renda complementar. As roças abandonadas sofreram um processo de sucessão ecológica e hoje se encontram quase inteiramente cobertas por florestas em estágio avançado de sucessão.

No segundo caso, o Maciço da Pedra Branca, localizado na zona oeste da cidade do Rio de Janeiro, teve uma parcela dos cultivos existentes mantidos, todavia coexiste com um acelerado processo de desenvolvimento das atividades urbanas em seu entorno e com a expansão da degradação do ecossistema florestal. 0 crescimento da malha urbana e o desmatamento em suas encostas imprimem hoje na paisagem grandes modificações no arranjo espacial de seus elementos e definem uma nova configuração. Por ser área de expansão urbana, ou seja, onde o crescimento da ocupação está ainda se processando em ritmo acelerado, o Maciço da Pedra Branca guarda em seu espaço traços de um conflito rural-urbano. Dessa forma, encontra-se ainda uma atmosfera rural em meio à crescente paisagem urbana que se constrói com suas contradições sociais. As propaladas vantagens da implantação de projetos de desenvolvimento do ecoturismo ainda não encontraram condições propícias, em função da desarticulação de políticas nesse sentido.

Enfatiza-se a criação de UCs de proteção integral. Duas situações foram estudadas: uma reserva biológica e um parque estadual. Tais 
situações se tornaram uma variável importante sob o ponto de vista das resultantes ecológicas e sob a perspectiva socioeconômica, antropológica e jurídica, uma vez que alteraram (de modo não exclusivo) as dinâmicas de trabalho e subsistência dessas populações, assim como interferiram nos critérios de classificação legais e técnico-científicos. Foram também estabelecidas regras sobre o que poderia ou não permanecer nesses espaços (objetos, pessoas, plantas e animais). Ao longo do texto, abordaremos alguns desses aspectos de acordo com os limites deste trabalho. Por ora, destaca-se que, por razões paradoxais e não previstas inicialmente pelos ideólogos das políticas de conservação da natureza, as UCs, passadas algumas décadas desde sua criação, tornaram-se lócus de múltiplas experiências de coexistência entre ambientes naturais e agrícolas, as quais estimulam a realização de estudos comparativos e interdisciplinares. 0 acúmulo de conhecimento sobre as formas pretéritas e atuais de interação homem-natureza nesses espaços protegidos desmistifica concepções a respeito da existência de uma suposta natureza intocada e, justamente por isso, coloca em termos mais amplos o debate sobre o que merece ser protegido nesses espaços.

A fim de compatibilizar a articulação entre as diferentes linguagens disciplinares de compreensão da paisagem, fazemos uso de fontes diversas de investigação neste trabalho, como: o estudo das marcas da paisagem por meio de trabalho de campo, o uso de pesquisa bibliográfica (documentos, depoimentos de moradores, de reportagens e artigos). Este trabalho, sobretudo, sintetiza e amplia estudos anteriores de autores como Fernandez (2009), Fernandez, Oliveira e Dias (2015), e Oliveira (2002; 2015).

\section{A CULTURA CAIÇARA, O USO DO AMBIENTE E O SISTEMA AGRÍCOLA NA ILHA GRANDE}

O acentuado desenvolvimento urbano-industrial na segunda metade do século passado fez surgir uma preocupação com os ecossistemas e espécies. Com o intuito de garantir ao menos a preservação de amostras destes ecossistemas, desenvolveu-se o conceito de áreas 
protegidas, as quais foram denominadas, no Brasil, de UCs. A ideologia conservacionista americana, presente na criação do primeiro parque brasileiro (Parque Nacional do Itatiaia), foi responsável pelo surgimento de uma dicotomia entre populações e áreas protegidas. Por esse motivo, o conceito de unidade de conservação permaneceu, por muito tempo, associado a áreas desabitadas e intocáveis (ADAMS, 1994).

As áreas protegidas têm sido consideradas espaços vazios de relações sociais, pois uma vez determinado o estatuto da proteção, predominam os valores universais e científicos de conservação da natureza (FERNANDEZ; OLIVEIRA; DIAS, 2015). Na maior parte das vezes, as áreas de preservação foram criadas em territórios habitados por populações tradicionais, normalmente com pouca escolaridade e sem títulos de propriedade de suas terras. Para a prática do ecoturismo nestas áreas, foi realizada a "limpeza" da paisagem na implantação das unidades. Consequentemente, as populações foram colocadas em uma situação de ilegalidade pautada, muitas vezes, numa visão biocentrista, a qual não leva em consideração a importância das pessoas no processo de construção da paisagem que se pretendia "conservar".

A cultura caiçara é característica do litoral dos estados do Rio de Janeiro, São Paulo e Paraná e foi, durante décadas, baseada, primordialmente, na pesca e em roças de subsistência. Em termos culturais, surgiu da miscigenação genética e cultural do colonizador português com o indígena do litoral, sofrendo mais tarde alguma influência do negro (ADAMS, 1994). Seus conhecimentos sobre os recursos naturais incluem formas de cultivo da terra, assim como sobre a fauna e a flora, sobre a classificação da natureza (etnossistemática e etnotaxonomia) e sobre a tecnologia de manejo. Mussolini (1980) atribui a definição dessa cultura, entre outros aspectos, ao tipo de vida mais fechada, visto que se desenvolveu no litoral, relativamente isolado das áreas urbanizadas em termos de produtos e influências.

Vestígios permitem a identificação segura de antigas moradias dos caiçaras na llha Grande, possivelmente datando dos primeiros anos do século XIX. São encontradas em numerosos pontos da mata de encosta 
na Reserva Biológica Estadual da Praia do Sul, atualmente encobertas por mata densa (Figura 1). A prática econômica centrava-se na subsistência e as roças desempenhavam um papel fundamental (OLIVEIRA, 2008).

O sistema de plantio utilizado pelos caiçaras, chamado de "roça de toco" ou "coivara", é conhecido de longa data no interior do país. Trata-se de uma herança indígena, como o próprio nome indica - significa empilhar e tornar a queimar troncos e galhos não consumidos em uma primeira queima. No entanto, a roça caiçara apresenta algumas diferenças em relação às demais, como o cultivo de plantas tintoriais para tingir redes de pesca nas áreas de pousio, a utilização de areia de praia para combate à saúva etc. Esse método de plantio é baseado na derrubada e queima da mata, seguindo-se um período de pousio para restauração da fertilidade do solo, podendo variar de quatro (tempo mínimo) a 50 anos - ou mais (SCHMIDT, 1958). Trata-se de uma estratégia de manejo de recursos na qual os campos cultivados são usados em rodízio, com o objetivo de explorar o capital energético e nutritivo acumulado no sistema solo/ vegetação das florestas (NEVES et al., 2012).

\section{Figura 1 - Ruína de fogão caiçara retomada pela floresta atlântica - Ilha Grande (RJ)}

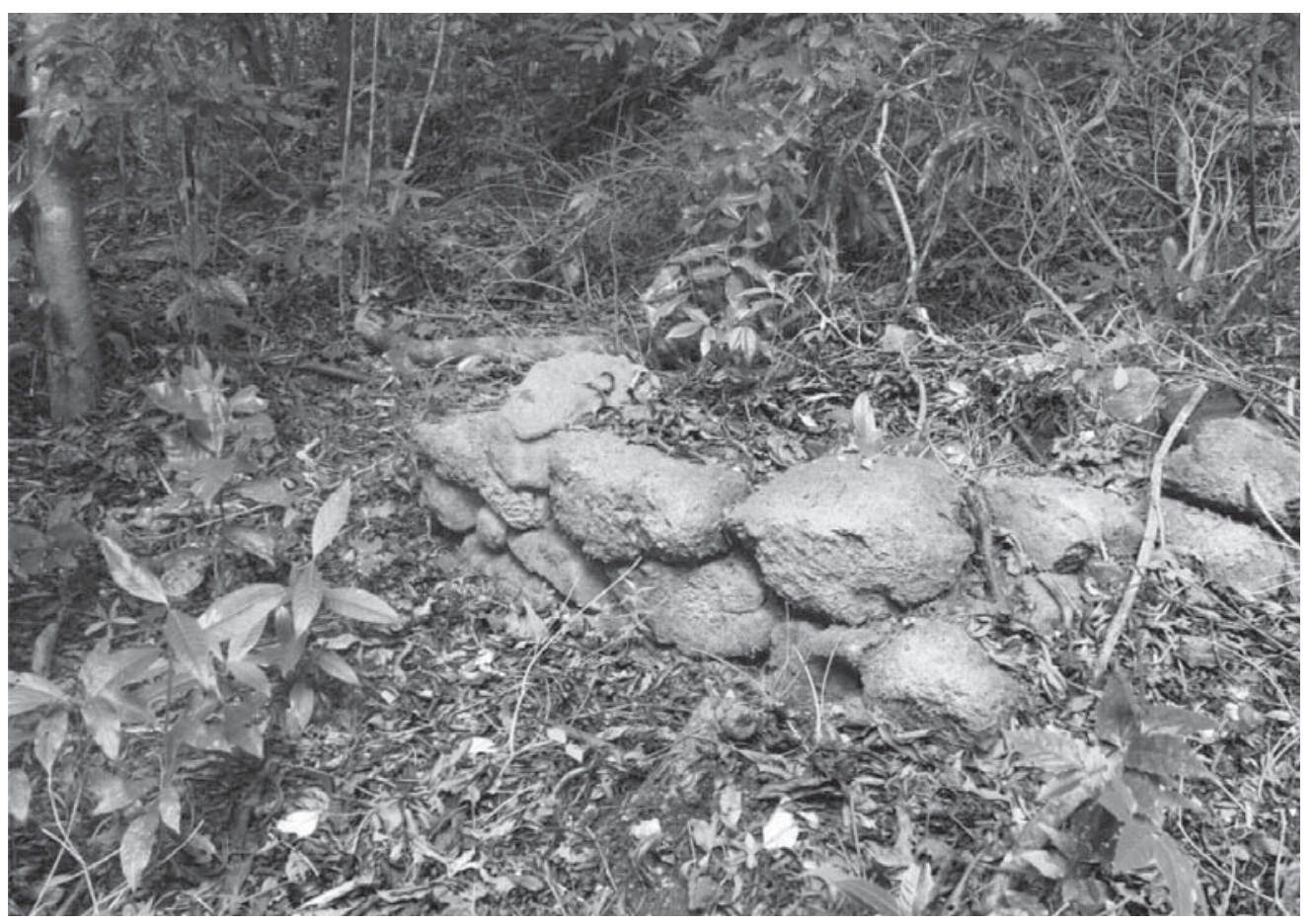


Quando ocorre a implantação das UCs nesses lugares, os primeiros atos administrativos consistem geralmente em sedentarizar os cultivos nômades, pois torna mais fácil o controle e o ensino de técnicas "modernas". No entanto, do ponto de vista da segurança do empreendimento, a agricultura migratória apresenta as seguintes vantagens, segundo Bronson (1972): a) minimização de riscos ambientais em função do relativo controle das populações de pragas e ervas daninhas; b) minimização do risco social: sem acesso formal à propriedade da terra, a agricultura migratória apresenta como vantagem em relação aos cultivos permanentes o fato de ser altamente flexível à expropriação, ou a alterações no contingente de mão de obra, uma vez que o prejuízo é apenas do trabalho de um ano; e c) em locais com solos pobres, agricultura migratória é muitas vezes a única alternativa possível de exploração econômica. Por outro lado, a contabilização energética costuma ser largamente favorável a esses empreendimentos em relação àqueles dependentes de subsídios externos (ALTIERI, 1987), porque, geralmente, estes são inacessíveis a essas populações.

Com relação ao impacto desse tipo de cultura sobre a paisagem, Ribeiro Filho et al. (2015) destacam a restauração da fertilidade, que ocorre no período de pousio e que é feita em grande parte, pelo retorno da matéria orgânica e nutrientes para a superfície do solo, via produção e subsequente decomposição da serapilheira. Trata-se do "descanso da terra", no dizer dos moradores locais, ao qual é inerente um controle permanente das taxas de biodiversidade e de biomassa do sistema, adequando-as às características de cada ciclo do agroecossistema.

Parece haver, no entanto, um número máximo de espécies e volume de biomassa desejável, que, ultrapassados, não trariam retorno palpável à fertilidade do solo e tornaria energeticamente mais dispendioso seu manejo. Os conceitos "terra braba" e "terra mansa" utilizados pelas caiçaras da llha Grande espelham, em certa medida, a taxa de diversidade e biomassa desejáveis para o agroecossistema em pousio. Os caiçaras denominam "terra braba" uma capoeira a qual ganhou aparência de floresta densa. A combinação da floresta densa com um período de alta diversidade e elevada biomassa gera dificuldade de manejo no local. Já 
a "terra mansa" significa um solo cujo ciclo pousio-cultivo vem sendo seguido em menores intervalos, logo tornando mais fácil seu manejo. Como se pode ver, a capoeira, por meio do manejo feito pelos caiçaras, passa a fazer parte integrante do ciclo agrícola, por seu papel na incorporação de nutrientes ao solo?2.

A vegetação instalada nas áreas de cultivo após seu abandono para pousio segue não apenas a disponibilidade de propágulos presentes, mas é selecionada pelas características do manejo caiçara. De acordo com Martins (2005), as áreas recém-abandonadas de roças caiçaras contribuem para promover a variabilidade genética da mandioca que lá permanece. Essa variabilidade, por meio de cruzamentos intra e interespecíficos, fornece uma reserva genética estratégica de propágulos ao agricultor.

O uso, ao longo do tempo dessa técnica baseada no pousio, pressupõe uma relativa mobilidade por parte dos agricultores. A Figura 2 apresenta um mapa dos vestígios de antigas moradias dos caiçaras na Reserva Biológica Estadual da Praia do Sul - tratam-se de cerca de 90 vestígios constituídos por ruínas de alicerces de pedras.

\section{Figura 2 - Ocorrência de ruínas de moradias caiçaras na floresta de encosta da Ilha Grande (RJ)}

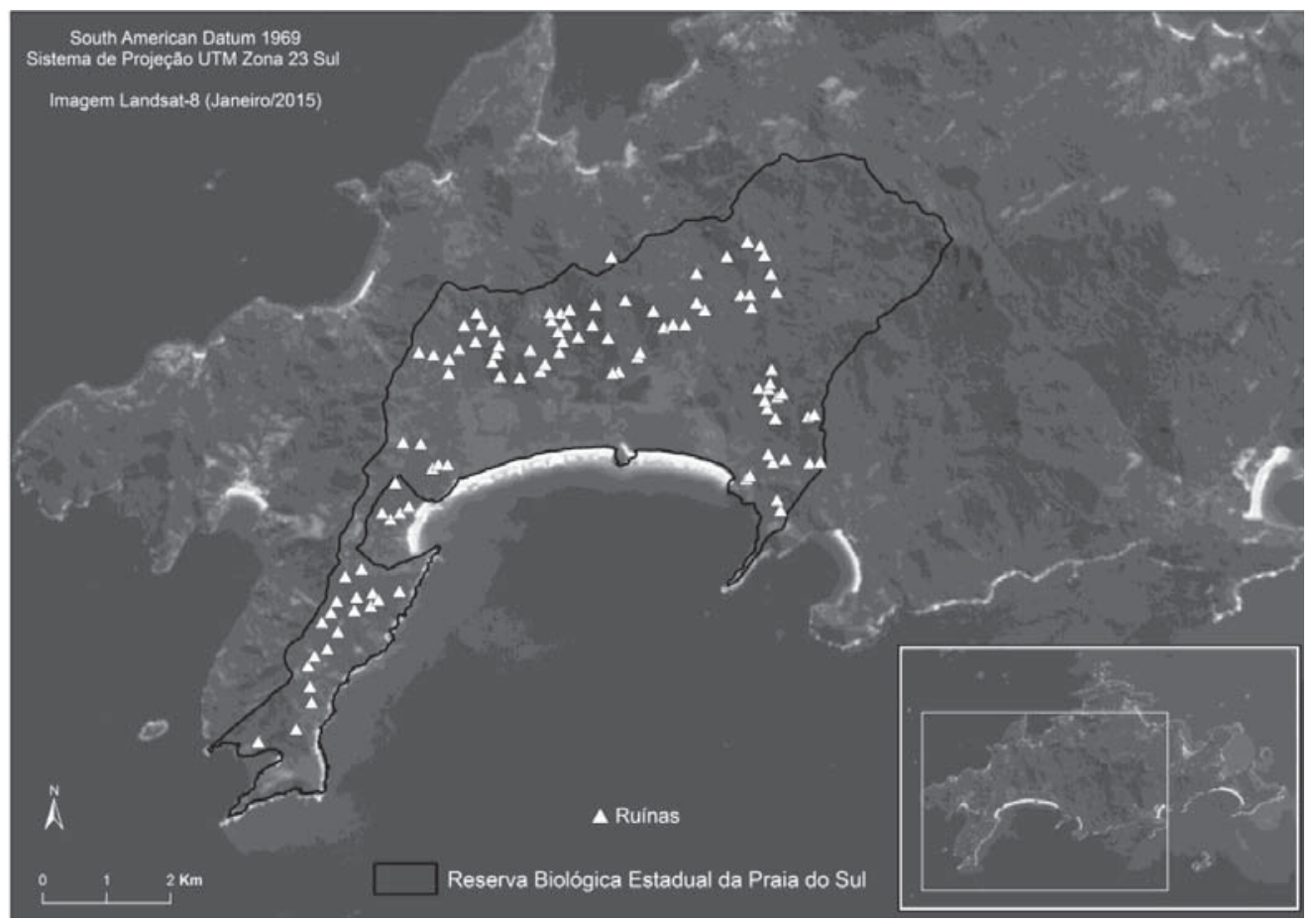

Fonte: Elaboração própria.

\footnotetext{
${ }^{2}$ A resolução 134, de 18 de janeiro de 2016, do Instituto Estadual do Ambiente (INEA - RJ) define critérios e procedimentos para a implantação, manejo e exploração de sistemas agroflorestais e para a prática do pousio no estado do Rio de Janeiro. 0 documento foi construído de forma conjunta pelo setor floresta deste órgão ambiental e os coletivos da Articulação de Agroecologia do Rio de Janeiro. Além de trazer segurança jurídica para os agentes ambientais e agricultores no manejo dos sistemas agroflorestais (SAFs) esse instrumento jurídico reflete o reconhecimento crescente das vantagens socioambientais das técnicas de pousio e de inovações crescentes em pesquisas sobre SAFs.
} 
Esses vestígios de ruínas encontram-se atualmente inteiramente recobertos pela Mata Atlântica em avançado estágio sucessional. Muitos deles devem remontar ao final do século XIX, chegando possivelmente à primeira metade do século XX.

A população caiçara enfrenta atualmente fortes pressões provocadas pela especulação imobiliária e o turismo. Há um declínio populacional em muitos pontos do litoral - por exemplo, a população residente na Vila do Aventureiro (localizada na Reserva Biológica Estadual da Praia de Sul) há cerca de 50 anos, era dez vezes maior do que a atual e era encontrada de forma mais espalhada do que se vê hoje, em função da dependência da agricultura de auto abastecimento. Informações orais levantadas na comunidade registram algo como mil moradores na comunidade do Aventureiro (quando hoje existem cerca de 120 habitantes). Esses moradores ocupavam quase toda a vertente meridional da Ilha Grande, sendo muito reduzida a população residente na vila propriamente dita. Segundo um informante: "os antigos eram do sertão"3.

O forte apelo turístico despertado em todo o entorno da Ilha Grande contribuiu para que os moradores da Praia do Aventureiro combinassem progressivamente suas atividades de subsistência com a organização de um turismo de base comunitária. Sabe-se que a maior integração com os mercados urbanos e o desenvolvimento das forças produtivas impõe necessidades crescentes de consumo, as quais podem levar as famílias a um estado de desequilíbrio (CANDIDO, 1971), ou seja, a produção não é suficiente para adquirir outros produtos que se tornaram essenciais.

Há, portanto, um progressivo abandono das atividades de subsistência e a busca de novas oportunidades no local ou em outros lugares. 0 crescimento das atividades turísticas no Aventureiro produziu acusações por parte de ambientalistas e funcionários do órgão responsável pela administração da reserva biológica, pois os moradores não seriam mais caiçaras e tampouco tradicionais.

${ }^{3}$ Esta constatação repetese com pequenas variações entre muitos informantes consultados.
Contudo, foi justamente a combinação do transporte de barco, do turismo comunitário, de algumas atividades de roça e da pesca que 
permitiram um equilíbrio das condições de reprodução social dos poucos caiçaras remanescentes na Praia do Aventureiro. A democratização de acesso a equipamentos domésticos modificou hábitos alimentares e facilitou o armazenamento de carnes e pescado, logo, contribuindo também para a diminuição da pressão sobre alguns recursos naturais.

Os conflitos com o órgão ambiental (atual Instituto Estadual do Ambiente), com novas regras de uso do território e valores ambientais, trouxeram novos parâmetros para que os moradores do Aventureiro olhassem sua própria história e encontrassem princípios sustentáveis em suas atividades cotidianas.

A tradição nesse sentido não deve ser vista como algo registrado no passado, mas como a afirmação da identidade de um grupo, a partir daquilo que é vivido e entendido como valioso e por isso mantido. É também a interpretação do passado à luz dos elementos do presente. Essa reelaboração ocorre na memória e também pela dinâmica da própria cultura e por meio do "olhar do outro" (dos visitantes, pesquisadores e agentes ambientais), que valorizou e chamou atenção para traços marcantes de seu modo de vida. 0 registro dessas memórias conta o que é ser "do Aventureiro" e ser "caiçara".

Assim, o caso do "Aventureiro" demonstra como o processo histórico nos reserva algumas surpresas. Na contramão de expectativas do desaparecimento dos modos de vida locais, os caiçaras da Praia do Aventureiro têm resistido e reivindicado sua anterioridade no território ao ato de criação da Reserva Biológica Praia do Sul. Esse grupo, com o apoio de diversos mediadores e após décadas de conflitos, ora latentes, ora abertos, conseguiu o feito inédito no âmbito das políticas ambientais estaduais: a realização da primeira recategorização do território de uma UC de proteção integral. Desse modo, 3\% da Reserva Biológica Estadual da Praia do Sul tornou-se uma Reserva de Desenvolvimento Sustentável (RDS) para conferir direitos territoriais a esses grupos e, ainda assim, protegê-los das investidas pesadas do capital imobiliário na região. 


\section{OS AGRICULTORES PERANTE A CIDADE NO MACIÇO DA PEDRA BRANCA}

O Maciço da Pedra Branca faz parte de uma vasta área do município do Rio de Janeiro - a Baixada de Jacarepaguá, Sepetiba, Guaratiba, Campo Grande e Santa Cruz - que no passado formava a zona rural da cidade, também denominada de "Sertão Carioca". Com o fim da produção açucareira e do breve ciclo do café carioca nesse vasto território, iniciouse um processo de desmembramento das grandes propriedades, as quais lentamente dão lugar aos sítios e chácaras. Assim, aos poucos se desenvolve uma produção orientada ao mercado local, combinada com culturas de subsistência. No entanto, de forma paralela a esses cultivos ocorreu, a partir do século XIX, a exploração do carvão no Maciço.

Essa atividade alterou de maneira significativa a coexistência de populações humanas e nos ambientes naturais da região. A fabricação do carvão era feita em plataformas escavadas na encosta, onde os carvoeiros improvisavam seus fornos, os "balões de carvão". Existem catalogadas mais de 1.000 dessas plataformas de fabricação de carvão no Maciço da Pedra Branca. A atividade dos carvoeiros, no Maciço da Pedra Branca, apresentou intensas repercussões na paisagem, com efeitos duradouros até o presente (OLIVEIRA, 2015).

À semelhança da floresta da Ilha Grande, a da Pedra Branca abriga um grande número de ruínas de moradias, sejam elas de carvoeiros, sejam elas de roceiros. A Figura 3 apresenta um inventário de 81 ruínas de moradias localizadas no interior da floresta. A maioria desses vestígios data do século XIX e são constituídos de alicerces de pedra de dimensões variadas nos quais predominava a junta seca, sem divisões internas, semelhantes às descritas por Guimarães et al. (2007).

As áreas do Maciço que se elevam acima da cota altimétrica de $100 m$ foram transformadas em parque estadual em 1974, englobando um território de 12.492 ha. Mesmo que a efetiva implantação do parque tenha se realizado gradativamente, a agricultura ali praticada passou a sofrer impedimentos para sua reprodução, por isso os agricultores foram 
relegados a uma condição de incerteza jurídica quanto a sua permanência nesse território. Contudo, deve-se destacar que a criação dessa UC acabou também preservando a atividade agrícola do processo de ocupação urbana e especulação imobiliária observada em seu entorno.

A atividade agrícola no Maciço da Pedra Branca deve ser compreendida em um contexto, no qual o rural tornou-se oficialmente urbano ${ }^{4}$, visto que as possibilidades de manutenção dos cultivos e o sustento da família tornaram-se cada vez mais difíceis. As dificuldades foram geradas ora pelas restrições da legislação ambiental, ora pela imposição crescente de novos padrões de consumo, ora pelas novas possibilidades de trajetórias dos filhos, ora pelas crescentes disputas pelo solo urbano, que impõem formas diversas de desterritorialização a esses produtores.

\section{Figura 3 - Localização de ruínas de moradias de carvoeiros e roceiros no interior da floresta do Maciço da Pedra Branca}

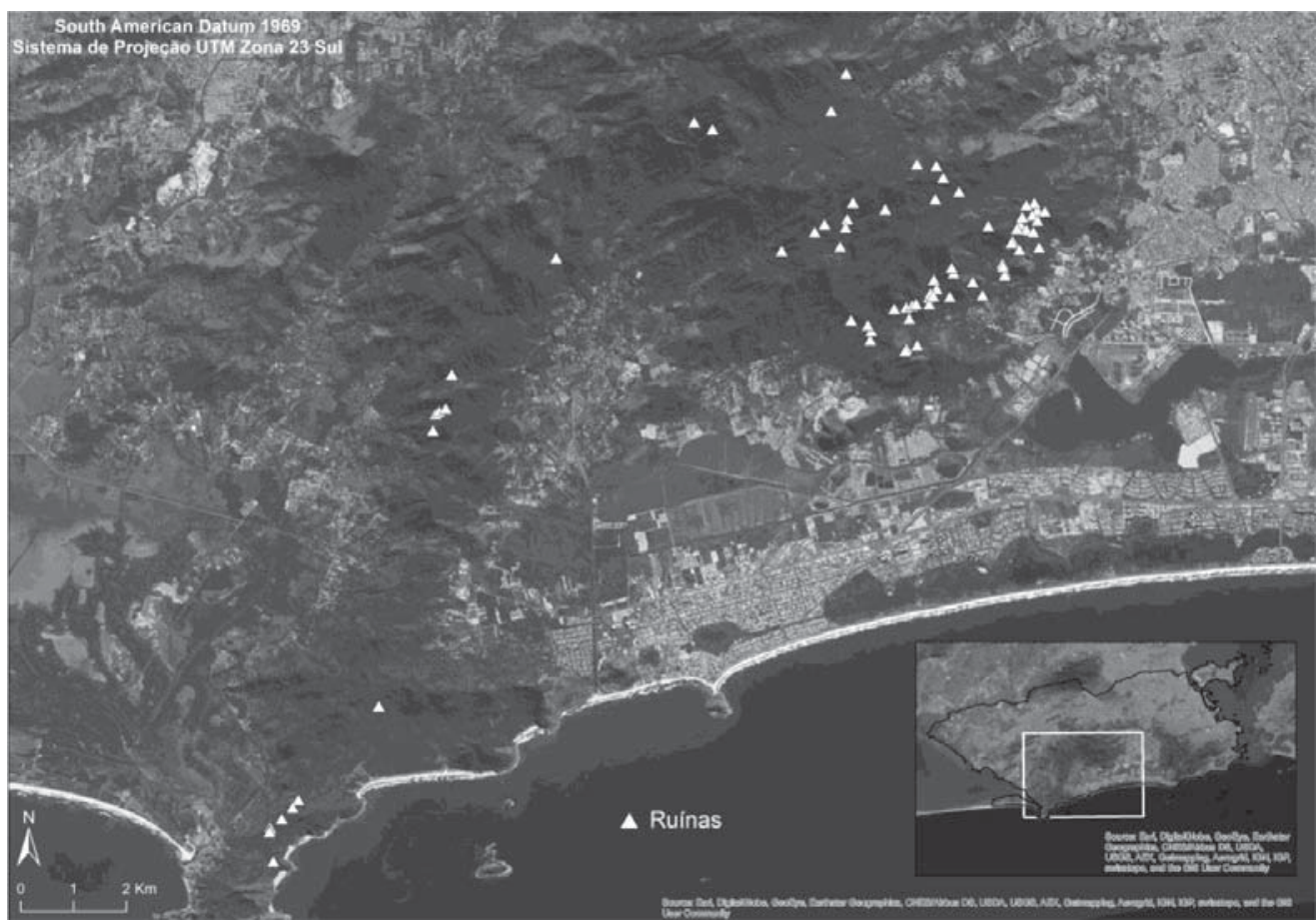

Fonte: Elaboração própria.

A despeito dessas adversidades, as atividades agrícolas no Maciço realizam-se, sobretudo, nas localidades de Rio da Prata (bairro de Campo Grande), Vargem Grande, Taquara e Ilha de Guaratiba. Há uma estimativa
4 Na década de 1960, foi extinta a Secretaria Municipal de Agricultura. A zona rural foi renomeada como zona oeste e seu atual plano diretor não reconhece a existência de territórios rurais no município. 
da existência de cerca de duzentas famílias de agricultores ${ }^{5}$. Seus cultivos são entremeados com trechos de floresta densa e ligados por caminhos rústicos.

Cerca de $87 \%$ dos agricultores afirmam ter a propriedade da terra, entendida aqui não apenas como uma forma de relação com a terra - comprovada por papéis ou documentos de compra - mas como uma forma de apropriação plena desse bem, ao longo do tempo. 37\% das famílias possuem seus sítios separados de suas moradias. Essa separação entre a unidade de produção e a unidade familiar se deve ao processo de migração dos sitiantes para as áreas mais baixas do Maciço, a fim de superar dificuldades cotidianas - de transporte, de acesso a escolas e de serviços de saúde (devido a distância) e de ausência de energia elétrica nos sítios - buscam maior proximidade com os centros urbanos.

Essas dinâmicas e impasses relativos à ocupação do Maciço podem ser identificadas pelas marcas na paisagem: as ruínas de casas, de escolas e até mesmo de um armazém nas cotas mais elevadas do Maciço (400 m). Além desses registros materiais, o depoimento de moradores mais antigos permite reconstituir os usos pretéritos e as formas de integração econômica e espacial com o meio urbano. Seu Enedino, agricultor da região do Rio da Prata, em Campo Grande, confirma essa tendência: "antes tinha muito mais gente aqui em cima, depois, foi concentrando lá embaixo" (comunicação verbal).

Assim, outrora, muito mais povoado do que hoje, o Maciço da Pedra Branca tinha suas partes altas ocupadas e os caminhos entre as encostas eram muito frequentados para alcançar os diversos bairros da cidade. Também encontramos no livro O sertão carioca (CORRÊA, 1933) uma verdadeira representação paisagística dessa localidade, marcada pelo tom

5 Os dados quantitativos apresentados neste trabalho foram retirados do relatório de pesquisa do Projeto Profito (2015), realizado no âmbito do Laboratório de Biodiversidade de Farmanguinhos (Fiocruz). de diagnóstico-denúncia, ao relatar a destruição dos recursos naturais e os impasses vividos por agricultores diante do processo de urbanização e desenvolvimento de novas relações de produção.

Colhidos os cachos nos pés, vão sendo arrumados nos caminhos, para depois serem transportados por burros aos depósitos de beira 
da estrada de rodagem e, daí conduzidos por autocaminhões ao centro de exportação, no centro urbano, ou por tropas, nos jacás das cangalhas dos burros. É verdadeiramente interessante veremse os cargueiros ou tropeiros que saem de todas as tocas da zona rural, alta noite, para chegarem, ao alvorecer, ao mercado, mas atualmente, as autoridades não os deixam passar de um certo ponto, por acharem vergonhosa a tropa. [...] Como verdadeiros abnegados, lutando contra todos os elementos e, finalmente abandonados por nossos dirigentes; quando por ventura, cometem qualquer delito, aplica-se-Ihes logo a lei, mas a lei feita para "almofadinha da cidade", não há compreensão de seu meio, de sua mentalidade e de sua vida rural, o que demonstra a necessidade do estudo do habitat rural, como faz a União Geográfica Internacional. [...] ao voltarem ao seu rancho trazem o que comer para o dia seguinte, em companhia de sua companheira e filhos. (CORRÊA, 1933, p. 142).

Também a disposição dos sítios e das casas é outro elemento importante para a construção de uma paisagem que conta a história de vida dessas pessoas e de seu habitar nesse espaço ao longo do tempo. "Ser nascido e criado" no Maciço não significa manter-se na mesma casa e propriedade por todo o tempo. Assim, são comuns os relatos: "eu nasci naquela casa, hoje é meu tio que mora lá", "minha casa foi herança de minha esposa", "meu pai alugou de minha avó, depois comprou", "aquele pedaço é meu, mas meu cunhado tem um bananal ali..." (FERNANDEZ; OLIVEIRA; DIAS, 2015).

Nesse sentido, pensar a coexistência entre os ambientes naturais e agrícolas implica considerar a complexidade dos sistemas agrícolas com todos seus elementos - plantas e animais, objetos, alimentos, as técnicas, formas de conhecimento e o espaço - já que a conservação in situ da agrobiodiversidade representa a proteção dos modos de vida correspondentes. Também sob a perspectiva da sociodiversidade, a engenhosidade e a riqueza cultural de técnicas de manejo agrícola também são por si mesmas merecedoras de proteção e patrimonializaçãó.

A cultura rústica da banana no Maciço da Pedra Branca envolve um saber especializado e muito antigo de manejo e observação dos bananais, da relação com os burros que transportam as frutas pelos

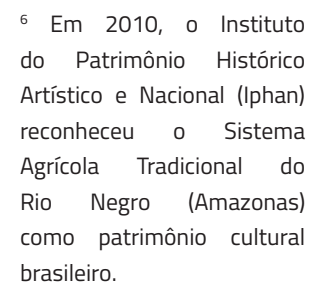


caminhos e as técnicas de amadurecimento correto. $\mathrm{O}$ agricultor Claudino, em depoimento na reportagem "O sertão carioca", publicada em um jornal de grande circulação, descreveu seu cotidiano:

O segredo é roçar duas vezes por ano, e deixar a terra se alimentar da própria bananeira. [...] Chega aqui eu tenho que cortar o cacho né, corto folha, forro as caixas tudo direitinho, arrumo, aí boto tudo no burro, carrego no burro, aí vou levar lá para baixo, para associação. Quando o tempo tá assim de sol, a gente bota quatro caixas em cima do burro e desce que é uma beleza, mas quando dá esses temporais, de chuva mesmo; trovoada, então o burro desce, tem vezes que escorrega, rola para grota abaixo, eu tenho que estar correndo, pegando, coitado, para não machucar os bichos. Para descer é brabo. A vida da gente é assim mesmo, tem que tocar para frente, não pode desanimar não. (CLAUDINO DA COSTA segundo BRISO; MARENCO, 2015, p. 13).

A banana e o caqui são os produtos mais importantes para o sustento das famílias de agricultores em todo o Maciço da Pedra Branca. Ambos são considerados lavouras de mercado e são cultivados junto com outros produtos que garantem o autoconsumo ou podem também ser comercializados. Entre os produtos mais citados pelos agricultores, destacam-se banana, caqui, aipim, manga, chuchu, milho, jiló, limão, taioba, abacate, jaca e quiabo. Os bananais e demais cultivos, além de garantirem a produção da vida, cumprem o papel de marcar na paisagem florestada a existência dos agricultores e de um sistema agrícola formado pelos caminhos, as casas de pau a pique, as cercas, os animais de carga.

A cultura da banana e do caqui no Maciço da Pedra Branca, no entanto, causa controvérsia entre biólogos, ambientalistas, geógrafos, agrônomos e outros por tratar-se de cultivos exóticos, portanto, não poderiam ser compatibilizados em UCs de proteção integral. Historicamente lembramos que essa dicotomia não existe. A atual floresta avançou sobre as áreas utilizadas para lavouras e a fabricação do carvão (FERNANDEZ; OLIVEIRA; DIAS, 2015).

0 reconhecimento da historicidade da paisagem em suas dimensões sociais e ecológicas pode contribuir para a solução de conflitos 
territoriais e socioambientais além da identificação de modelos mais sustentáveis de produção agrícola e conservação da natureza. Estudos como o de Solórzano, Guedes-Bruni e Oliveira (2012) comprovam o reduzido potencial de invasibilidade da banana. Freitas (2003), por sua vez, ao estudar o potencial erosivo do cultivo da banana no Maciço da Pedra Branca, conclui que seus efeitos são desprezíveis.

Também confirmando essa perspectiva, o Plano de Manejo do Parque Estadual da Pedra Branca, publicado em 2013, reconhece o bom estado de conservação nas áreas do parque onde coexiste a atividade agrícola. Segundo o documento, ao referir-se à área de Vargem Grande:

AEI7 Vargem Grande abrange pequenas áreas de restauração e de floresta em estágio inicial, e grande parte da sua extensão ocupada por florestas em estágio médio ou avançado. [...] Mesmo não tendo áreas de favela nesta região, existem pequenos produtores rurais que vivem com menos de 1 salário mínimo e sem acesso à infraestrutura de água, luz, saneamento, saúde e educação. [...] As áreas de cultivo desta AEI são muito menores do que as da zona oeste e estão, predominantemente, associadas à cultura de banana, mas também ocorre o plantio de hortaliças. Dentre as áreas de ocupação antrópica encontra-se a comunidade da Astrogilda, onde ocorrem indícios da descendência quilombola, mas ainda sem confirmação. (RIO DE JANEIRO, 2013).

O escoamento da produção é uma das dificuldades para a comercialização dos produtos. A "puxada" da banana e do caqui necessitam da utilização de animais de trabalho, combinada com a utilização de outros meios de transporte para chegar às feiras ou pontos de venda. A presença das mulas e cavalos no Maciço da Pedra Branca é um fator significativo para a transformação da paisagem.

A necessidade de pastagens para as tropas que por lá circulam remete a uma característica marcante ligada à utilização direta da biomassa de florestas tropicais por muares e equinos. Isso é impalatável pela fauna que não evoluiu com o ecossistema, como esses animais. Sua fitomassa é formada por grande número de compostos secundários, sendo os mais frequentes os taninos, compostos terpenoides,

` Área Estratégica Interna.

${ }^{8} \mathrm{O}$ reconhecimento formal da identidade quilombola ocorre em agosto de 2014, pela Fundação Palmares. 
alcaloides e glicosídeos. Altas concentrações de taninos e características esclerófilas podem constituir barreiras para a alimentação de herbívoros não especialistas (OLIVEIRA, 2015). Assim, a coexistência de muares, humanos e florestas pressupõe obrigatoriamente a existência de pastagens (para uso direto pelos animais) ou de capineiras, onde gramíneas de porte elevado são plantadas para prover forragem aos animais. Essa solução é frequentemente utilizada no Maciço da Pedra Branca (Figura 4).

Figura 4 - Transporte de capim-napiê (Pennisetum sp.) para alimentação de outros muares em plantios próximos à floresta do Maciço da Pedra Branca

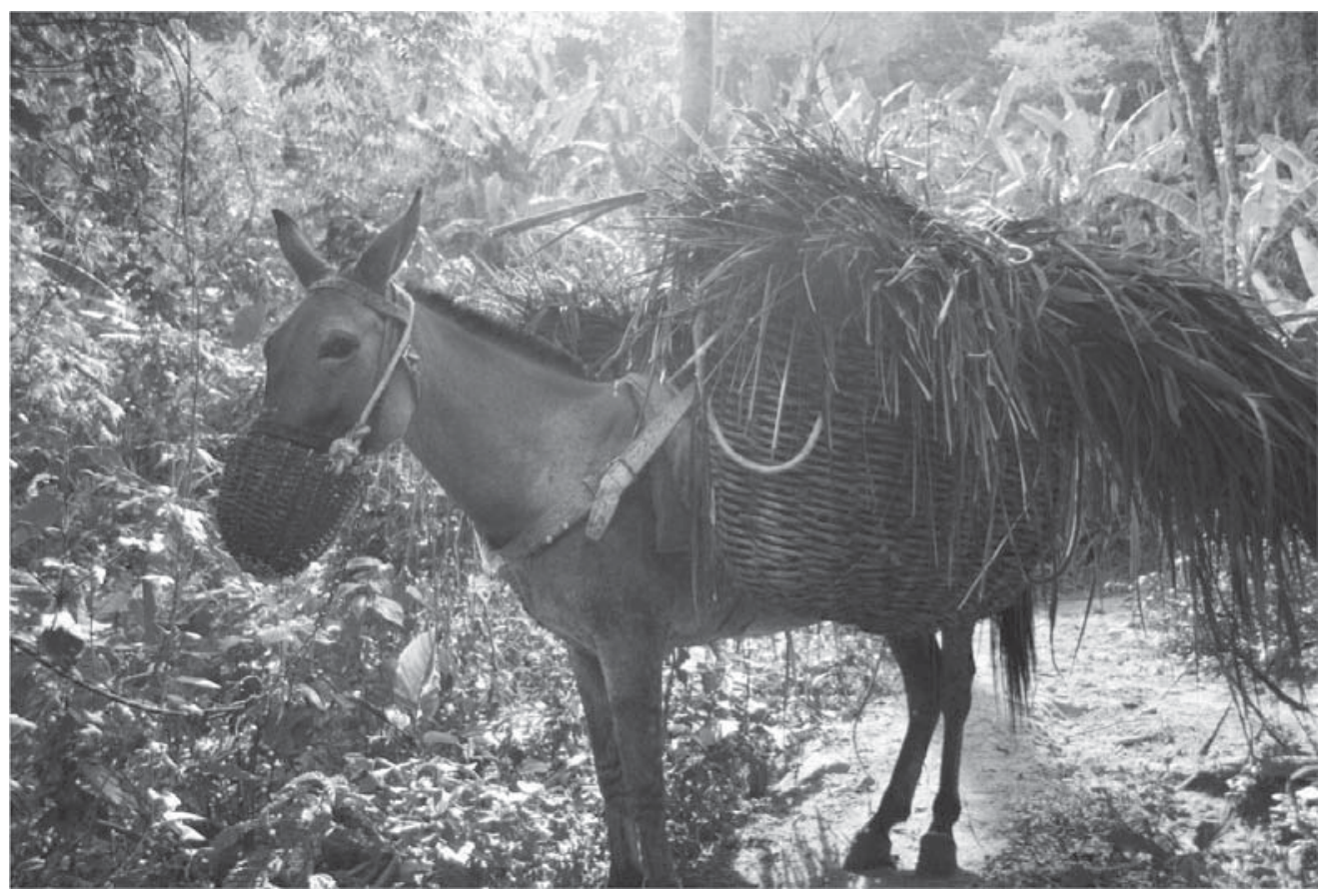

Foto: Rogério Oliveira.

Desde meados da década de 2000, uma parcela dos agricultores do Maciço da Pedra Branca tem adaptado seu processo de cultivo aos métodos orgânicos e aos princípios da agroecologia. Esse movimento permitiu a participação dos agricultores no Circuito Carioca de Feiras Orgânicas, inaugurado em 2010, e a divulgação de seus modos de vida e a expansão de seus circuitos de comercialização em outros bairros da cidade. Segundo relatos dos agricultores, os consumidores querem saber como eles plantam, onde e como eles vivem (FERNANDEZ, 2009). 
A humanização das relações de troca entre agricultores e consumidores tem incentivado novas iniciativas de turismo comunitário, que podem resultar na produção de diferentes arranjos entre a agricultura e roteiros de visitação local.

Há nos mercados orgânicos e agroecológicos uma crescente percepção da conexão entre os processos de produção e o modo de vida do produtor. Este é caracterizado pelo acesso a terra, pela organização do trabalho familiar, pela produção do alimento sem agrotóxicos etc. São valorizados os aspectos rústicos e tradicionais do cultivo de alimentos e o agricultor passa a ser visto não apenas por sua condição de colocar produtos no mercado, mas como um ator fundamental para a manutenção de um sistema agroalimentar integrado à cidade.

A crescente notoriedade dos modos de vida agrícolas no "Sertão Carioca" - fruto não apenas das práticas de mercado, mas também de ações de mobilização e reivindicação de direitos territoriais - resultou em agosto de 2014 no reconhecimento pela Fundação Palmares de duas comunidades quilombolas no Maciço da Pedra Branca: a Comunidade Cafundá Astrogilda e a Comunidade do Camorim.

A despeito dessa conquista, outras comunidades portadoras de modos de vida tradicionais no Maciço ainda não obtiveram o mesmo reconhecimento. Ressaltam-se as condições históricas em que a agricultura ali se desenvolveu, conformada pelas restrições ambientais, permanecendo com características que se adequam à definição apresentada pelos antropólogos Manuela Carneiro da Cunha e Mauro de Almeida, ao definirem que a tradicionalidade também se dá pelo:

[...] uso de técnicas ambientais de baixo impacto, formas equitativas de organização social e traços culturais que são seletivamente reafirmados e reelaborados além de relativa simbiose com a natureza, pelo conhecimento aprofundado da natureza e pela noção de território onde se reproduzem econômica e socialmente. (SANTILLI, 2005,).

Assim, tanto no caso da Ilha Grande quanto do Maciço da Pedra Branca, os condicionantes externos desempenham um papel 
predominante em termos de transformação dos modos de vida, embora assumam diferentes historicidades.

\section{CONSIDERAÇÕES FINAIS}

Ao descrever o caso da Praia do Aventureiro, na Ilha Grande e do Maciço da Pedra Branca, na cidade do Rio de Janeiro, apresentamos duas situações semelhantes de coexistência entre ambientes naturais e agrícolas. Identificamos processos análogos de resistência e manutenção de modos de vida tradicionais, mas com resultantes ecológicas e práticas socioeconômicas distintas. Do ponto de vista do uso histórico, o Maciço da Pedra Branca difere-se da Ilha Grande por conta da atividade pretérita dos carvoeiros. As roças, no entanto, nos dois locais, assemelham-se em sua forma e manejo, embora a sedentarização dos cultivos seja maior no Pedra Branca. Buscamos, desse modo, demonstrar as contribuições teórico-metodológicas de uma perspectiva interdisciplinar do estudo da paisagem e das formas da construção histórica da interação homemnatureza.

Ambos os grupos estudados, estabelecendo atividades econômicas de subsistência (ainda que inseridas nos mercados) de agricultura ou pesca, viram-se ameaçados pela expansão de relações de produção capitalistas, com novas racionalidades sobre a organização do trabalho e uso do solo. Nos dois casos, a criação de UCs de proteção integral buscou intervir e impedir a destruição dos ecossistemas dos respectivos territórios, sem, contudo, reconhecer os modos de vida das populações e suas formas de coexistência com o ambiente natural.

Se por um lado o ato legal de criação das UCs trouxe severas restrições materiais e simbólicas às populações locais, também estimulou, nos dois casos, formas de resistência e lutas por direitos territoriais que resultaram no reconhecimento de identidades tradicionais e no desenvolvimento de atividades econômicas não subordinadas e sustentáveis. No caso do Aventureiro, houve o declínio do cultivo das roças e a crescente regeneração das florestas, em função da expansão das atividades de turismo comunitário. 
No caso da Pedra Branca, as atividades agrícolas são expressivamente menores do que as existentes na década de 1970. Nessa perspectiva, também houve a recuperação de parte substantiva da floresta. A despeito de todas as dificuldades de reprodução da agricultura em um espaço urbano como é o caso do Maciço da Pedra Branca, a notoriedade dessa agricultura local, ainda praticada com técnicas rústicas e de baixo impacto ambiental nos mercados orgânicos e agroecológicos, tem resultado em novas experimentações socioambientais e em práticas de agrofloresta que podem garantir sua longevidade.

Enquanto na Praia do Aventureiro a identidade caiçara e sua tradicionalidade podem ser afirmadas sem a manutenção da atividade agrícola, em contrapartida, no Maciço da Pedra Branca, elas são condição fundamental de reivindicação territorial e de estímulo às atividades de turismo comunitário. Em ambos os casos, no entanto, ficam claros os distintos processos de transição cultural por que passam as populações tradicionais.

\section{Referências}

ADAMS, C. As florestas virgens manejadas. Boletim do Museu Paraense Emílio Goeldi: Ciências Humanas, Belém, v. 10, n.1, p. 3-20, 1994.

ALTIERI, M. A. Agroecology: the scientific basis of alternative agriculture. 1. ed. London: Westview Press, 1987.

BALÉE, W. E. The research program of historical ecology. Annual Review of Anthropology, Palo Alto, v. 35, p. 75-98, 2006.

BRISO, C. B.; MARENCO, D. O sertão carioca. O Globo, Rio de Janeiro, 4 out. 2015. Seção Sociedade. Disponível em: <http://glo.bo/2hdD90j>. Acesso em: 5 fev. 2016.

BRONSON, B. Farm labor and the evolution of food production. In: SPOONER, B. (Ed.). Population growth: antropological implications. Cambridge: The MIT Press, 1972. p. 315-337. 
CANDIDO, A. Parceiros do Rio Bonito. 1. ed. São Paulo: Duas Cidades, 1971.

CHAZDON, R. L. Second growth: the promise of tropical forest regeneration in an age of deforestation. 1. ed. Chicago: University of Chicago Press, 2014.

CORRÊA, A. M. 0 sertão carioca. 1. ed. Rio de Janeiro: Imprensa Nacional, 1933.

COSTA, G. V. L. A construção da autoridade entre os donos de barco do Aventureiro, Ilha Grande - RJ: uma etnografia das relações de poder. Revista Sociedade e Estado, Brasília, DF, v. 26, n. 30, p. 501-520, 2011.

FERnANDEZ, A. C. F. Do sertão carioca ao Parque Estadual da Pedra Branca: a construção social de uma unidade de conservação à luz das políticas ambientais fluminenses e da evolução urbana do Rio de Janeiro. 2009. 376 f. Tese (Doutorado em Sociologia) - Programa de Pós-Graduação em Sociologia e Antropologia, Universidade Federal do Rio de Janeiro, Rio de Janeiro, 2009.

FERNANDEZ, A. C. F.; OLIVEIRA, R. R.; DIAS, M. C. O. Plantas exóticas, populações nativas: humanos e não humanos na paisagem de uma UC de Proteção Integral. Tessituras: Revista de Antropologia e Arqueologia, Pelotas, v. 3, n. 1, p. 121-153, 2015.

FREITAS, M. M. Funcionalidade hidrológica dos cultivos de banana e territorialidades na paisagem do Parque Municipal de Grumari - Maciço da Pedra Branca - RJ. 2003. 387 f. Tese (Doutorado em Geografia) Programa de Pós-Graduação em Geografia, Universidade Federal do Rio de Janeiro, Rio de Janeiro, 2003.

GUIMARÃES, C. M.; NASCIMENTO, E. L. M.; VELOSO, G. P. Arqueologia e campesinato: vestígios de uma categoria social. Vestígios: Revista LatinoAmericana de Arqueologia Histórica, v. 1, n. 1, p. 93-131, 2007.

MARTINS, P. S. Dinâmica evolutiva em roças de caboclos amazônicos. Estudos Avançados, São Paulo, v. 19, n. 53, p. 209-220, 2005. 
MUSSOLINI, G. Ensaios de antropologia indígena e caiçara. 1. ed. Rio de Janeiro: Paz e Terra, 1980. 288 p.

NEVES, W. A. et al. Coivara: cultivo itinerante na floresta tropical. Ciência Hoje, Rio de Janeiro, v. 50, p. 26-30, 2012.

OLIVEIRA, R. R. Ação antrópica e resultantes sobre a estrutura e composição da Mata Atlântica na Ilha Grande, RJ. Rodriguésia, Rio de Janeiro, v. 53, n. 82, p. 33-58, 2002.

Fruto da terra e do trabalho humano: paleoterritórios e diversidade da Mata Atlântica no Sudeste brasileiro. Revista de História Regional, Ponta Grossa, v. 20, n. 2, p. 277-299, 2015.

When the shifting agriculture is gone: functionality of Atlantic Coastal Forest in abandoned farming sites. Boletim do Museu Paraense Emílio Goeldi: Ciências Humanas, Belém, v. 3, n. 2, p. 213-226, 2008.

OLIVEIRA, R. R.; ENGEMANN, C. História da paisagem e paisagens sem história: a presença humana na Floresta Atlântica do Sudeste Brasileiro. Esboços, Florianópolis, v. 18, n. 25, p. 9-31, 2012.

OUIS, P.; JENSEN, L. "I brought a hazelnut from Macedonia": cultural and biological diversity in a globalizing world. In: BJÖRK, F.; ELIASSON, P.; POULSEN, B. (Eds.). Transcending boundaries: environmental histories from the Øresund region. Malmö: Malmö Universtity, 2009. p. 127-141.

RAFFESTIN, C. E se a representação fosse apenas a invenção da moeda fiduciária do real? Formação, Presidente Prudente, v. 2, n. 14, p. 8-13, 2007.

RIBEIRO FILHO, A. A. et al. Dynamics of soil chemical properties in shifting cultivation systems in the tropics: a meta-analysis. Soil Use and Management, Nova York, v. 31, n. 4, p. 474-482, 2015.

RIO DE JANEIRO (Estado). Secretaria de Estado do Ambiente. Parque Estadual da Pedra Branca: plano de manejo. Rio de Janeiro, 2013. Disponível em: <http://bit.ly/2ghmg84>. Acesso em 12 abr. 2016. 
SANTILLI, J. Sociambientalismo e novos direitos: proteção jurídica à diversidade biológica e cultural. São Paulo: Peirópolis, 2005.

SCHMIDT, C. B. A lavoura caiçara. Documentário da vida rural 14. Rio de Janeiro: Serviço de Informação Agrícola, 1958.

SIMMEL, G. A filosofia da paisagem. 1. ed. Covilha: Lusofia Press, 2009.

SOLÓRZANO, A.; GUEDES-BRUNI, R. R.; OLIVEIRA, R. R. Composição florística e estrutura de um trecho de Floresta Ombrófila Densa Atlântica com uso pretérito de produção de banana, no Parque Estadual da Pedra Branca, Rio de Janeiro, RJ. Revista Árvore, Viçosa, v. 36, p. 451-462, 2012.

Recebido: 29/05/2016

Aprovado: 03/10/2016 